\title{
EXTENSION OF ASTM E2283 STANDARD PRACTICE FOR THE ASSESSMENT OF LARGE EXOGENOUS NONMETALLIC INCLUSIONS IN SUPER DUTY STEELS
}

\author{
A. A. Kazakov ${ }^{1}$, A. I. Zhitenev ${ }^{1}$, M. A. Salynova1 \\ 1 Peter the Great St. Petersburg Polytechnic University (St. Petersburg, Russia)
}

E-mail: kazakov@thixomet.ru; zhitenev@thixomet.ru

\section{AUTHOR'S INFO}

A. A. Kazakov, Dr. Eng., Prof., Head of "Metallurgical Examination" Lab.

A. I. Zhitenev, Engineer, "Metallurgical Examination" Lab.

M. A. Salynova, Engineer, "Metallurgical Examination" Lab.

\section{Key words:}

ASTM E2283, single large nonmetallic inclusions, indigenous, exogenous, metallographic assessment, extreme value analysis, super duty steel.

\author{
A B S T RACT
}

The practice for extreme value analysis of nonmetallic inclusions described in ASTM E2283 has been applied to the examples for assessing the nonmetallic inclusions in super duty steels. An original interpretation of the measurement results obtained according to ASTM E2283 technique has been proposed, which allows extending the limits of the scope of this standard to also evaluate exogenous inclusions. This study has shown that the practice defined in ASTM E2283 can be used to identify a random, single exogenous inclusion among the largest indigenous nonmetallic inclusions, as well as to predict the longest exogenous inclusions, if they have a systemic source of penetration into the melt and are described by the corresponding Gumbel distribution.

It has been found that the modern level of secondary metallurgy can produce steels with low indigenous nonmetallic inclusion ratings; however, failures of the pouring and casting technology can lead to the presence of coarse exogenous nonmetallic inclusions in the finished metal products.

\section{Introduction}

The presence of large nonmetallic inclusions (NMIs) in super duty steels have a decisive influence on the properties of the finished products [1,2].

In fact, nonmetallic inclusions larger than $100 \mu \mathrm{m}$ significantly reduce the results of acceptance tests of steels for nuclear reactor vessels, such as ductility and toughness test results [3-6], while the fine NMIs less than $10 \mu \mathrm{m}$ in size cause degradation of steel during its operation under the radiation [7-9].

The number of the largest NMIs in steel, as a rule, does not exceed 5\% of their total number and; therefore, with a high probability these NMIs can be attributed to exogenous inclusions, as was shown in the paper [10]. The remaining $95 \%$ of NMIs were evaluated according to ASTM E1245 with accuracy good enough to establish the pattern of their distribution over the thickness of the top and bottom rings. This pattern was in accordance with the solidification features of an extremely large ingot of $15 \mathrm{Cr} 2 \mathrm{NiMoV}$ steel [10] weighing 420 tons. These large exogenous NMIs were distributed stochastically over the cross-section of these rings; therefore, stereological methods implemented in ASTM E1245 are not suitable for their assessment.

Nonmetallic inclusion ratings of steel in many respects defines useful properties of railway wheels [1]; therefore, they utilize a quantitative metallographic inspection [11] in accordance with ASTM E1245 [12]. An analysis of the acceptance tests results of the wheels [13] showed that the average volume fraction of oxides and sulfides did not exceed 0.005 vol. \%, which is 20 times lower than the maximum level for the final quality check of railway wheels. However, in the worst field of view of some specimens, single large exogenous nonmetallic inclusions with a volume fraction significantly exceeding the acceptable 0.2 vol. $\%$ could be found. Such NMIs larger than $60 \mu \mathrm{m}$ have a decisive negative influence on the service performance of the finished products [14]; but, due to their stochastic distribution in volume they cannot be estimated by the stereological methods used today in industry.

The size of the largest NMIs which can be found in the above-mentioned steels can be estimated by ASTM E2283 [18], but first the extreme value distribution has to be created based only upon measurements of the largest NMIs. The continuous random variable $\mathrm{x}$ has a two- $\mathrm{pa}-$ rameter extreme value distribution (Gumbel distribution) if the probability density function is given by the following equation $[15,16,18]$ :

$$
\begin{aligned}
& f(x)=\frac{1}{\delta} \exp (-y) \cdot \exp (-\exp (-y)), \\
& y=\frac{x-\lambda}{\delta}
\end{aligned}
$$

where $x$ - maximum Feret's diameter of the largest inclusion in each control area, $\mathrm{A}_{0}, \mu \mathrm{m} ; \delta$ and $\lambda$ - the location and scale parameters of the extreme value distribution function; respectively, and $y$ - reduced variate.

According to ASTM E2283, for each of the six investigated specimens on the four cross sections with an area of $150 \mathrm{~mm}^{2}$ for each of them, the largest maximum Feret's diameter of the measured inclusions was recorded. This will result in a set of 24 maximum Feret's diameters. In order to create each new cross section, at least $0.3 \mathrm{~mm}$ of material have to be removed by repolishing a specimen. 

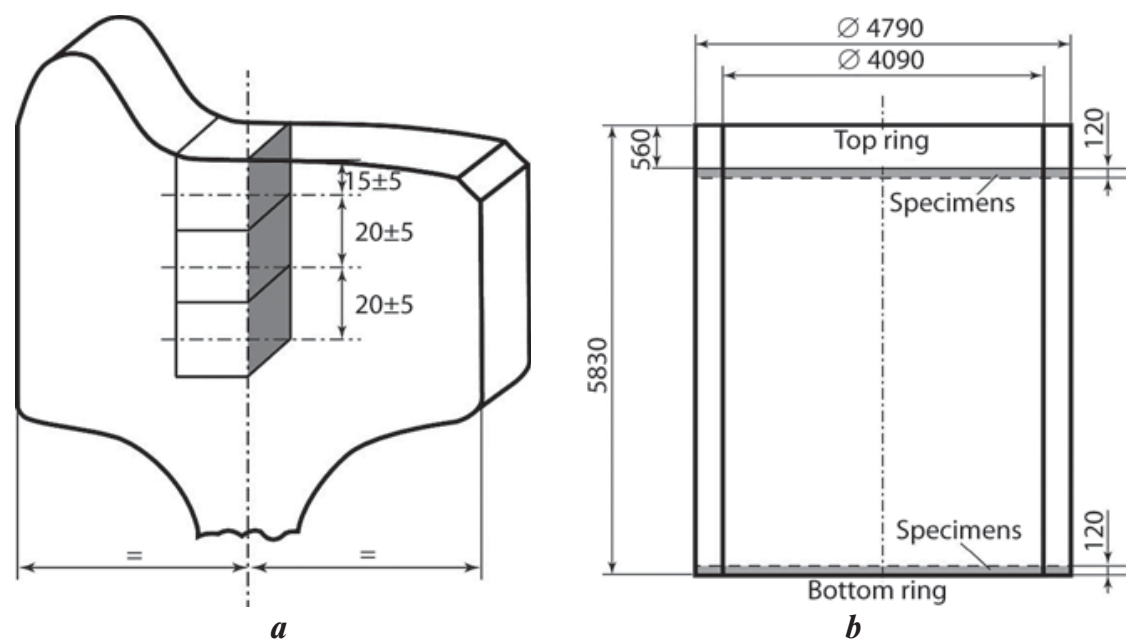

Fig. 1. Sampling schemes for wheels ( $a$ ) and forging (b)

To predict the sizes of the maximum NMIs expected to be in these steels, the Gumbel distribution parameters have to be defined. Such processing of the measurement results during acceptance tests of railway wheels will make it possible to predict the probability of the appearance of harmful large indigenous NMIs, even if, according to the results of additional extended acceptance tests, the railway wheels were recognized to be ready for service use [13]. This is extremely important for the properties of train wheels, which depend not so much on uniformly distributed small indigenous NMIs but mainly on the presence of individual large exogenous NMIs [2, 17], which according to any standard, for example, ASTM E1245 [12] or ASTM E2283 [18], are not evaluated and must be detected by non-destructive inspection methods, such as ultrasonic inspection.

Therefore, the aim of this work is to expand the Scope, as well as Significance and Use of the ASTM E2283 to assess not only indigenous, but also exogenous inclusions, particularly for the performance of super duty steels.

\section{Materials and Methods}

The investigated specimens were sampled from the railway wheels (Fig. 1, a) of three heats of Class $C$ wheel steel [11], which were deoxidized and modified according to different technologies, as well as specimens sampled from the forging (Fig. 1, $\boldsymbol{b}$ ) made from a extra-large ingot of 420 tons of $15 \mathrm{Cr} 2 \mathrm{NiMoV}$ steel [10].

Wheel steel heats \#1 and \#3 were preliminary deoxidized during the pouring off from the LD converter (LDC) with pig aluminum at a rate of $0.1 \mathrm{~kg}$ per ton of steel; and then were finally deoxidized after ladle furnace treatment with an aluminum wire rod at a rate of $0.2 \mathrm{~kg}$ per ton of steel. After recirculation degassing, the steel was modified with calcium by flux-cored wire of grade $\mathrm{SiCa} 30$ with a rate of 1.2 and $0.5 \mathrm{~kg}$ per ton of steel in heats $\# 1$ and $\# 3$, respectively. Heat \#2 was deoxidized with aluminum at pouring off from LDC with a high consumption of aluminum of $0.3 \mathrm{~kg}$ per ton of steel; then it was processed through ladle furnace treatment, degassed, and before casting it was treated with flux-cored $\mathrm{SiCa} 30$ wire at a rate of $1.4 \mathrm{~kg}$ per ton of steel. Steel $15 \mathrm{Cr} 2 \mathrm{NiMoV}$ was manufactured using complex deoxidizers with the double degassing treatment and multiladles pouring off [2].

The specimens were prepared using Buehler equipment and consumables. Nonmetallic inclusion assessment of the steel specimens was carried out according to ASTM E2283 by using a Zeiss Axiovert 200 MAT optical microscope equipped with a Thixomet PRO automatic image analyzer.

The chemical composition of NMIs was determined using a Zeiss Supra equipped with an energy-dispersive $\mathrm{X}$-ray spectrometer (SEM-EDS method).

\section{Results, their Processing and Discussion}

Researchers have made numerous attempts to expand the capabilities of extreme value statistics for estimation NMIs. For example, the authors [19-21] suggested estimating the size of NMIs on the fracture surface of specimens or on each individual inclusion isolated from a metal by electrolytic dissolution. In other works, instead of the Gumbel distribution, the other distributions of extreme values were used: Weibull or Fréchet [22-24] and Pareto [25, 26]. However, the advantages of such methods and the novelty of the results obtained in these works [19-21] do not justify the com-

\begin{tabular}{|c|c|c|c|}
\hline $\begin{array}{l}\text { Table 1. Parameters of unique } \\
\text { for indigenous and exogenous } \\
\text { in the investigated specimens }\end{array}$ & $\begin{array}{l}\text { aumbel distrib } \\
\text { inclusions }\end{array}$ & & \\
\hline Steel & Heat & $\delta$ & $\lambda$ \\
\hline \multirow{4}{*}{ Wheel steel, Class C } & $\# 1$ & 6,4 & 20,2 \\
\hline & $\# 2$ & 4,3 & 18,0 \\
\hline & \#3, indigenous & 1,4 & 11,1 \\
\hline & $\# 3$, exogenous & 47,9 & 79,2 \\
\hline \multirow{2}{*}{$\begin{array}{l}\text { Forging from extra-large ingot, } \\
\text { 15Cr2NiMoV steel }\end{array}$} & bottom ring & 43,0 & 111,9 \\
\hline & top ring & 61,1 & 142,4 \\
\hline
\end{tabular}




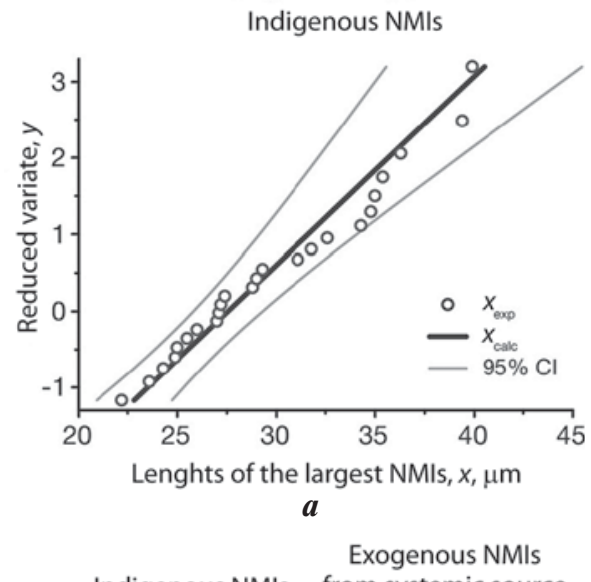

Indigenous NMls from systemic source

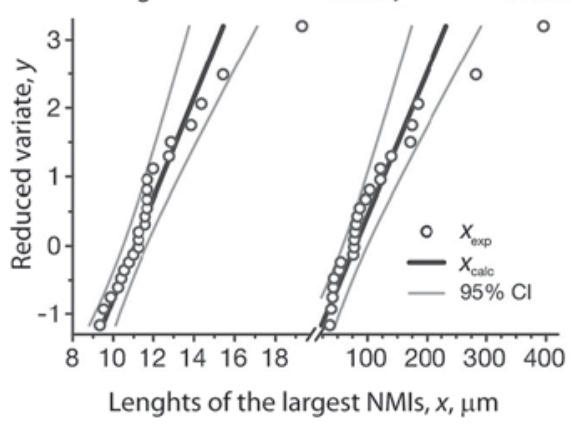

c

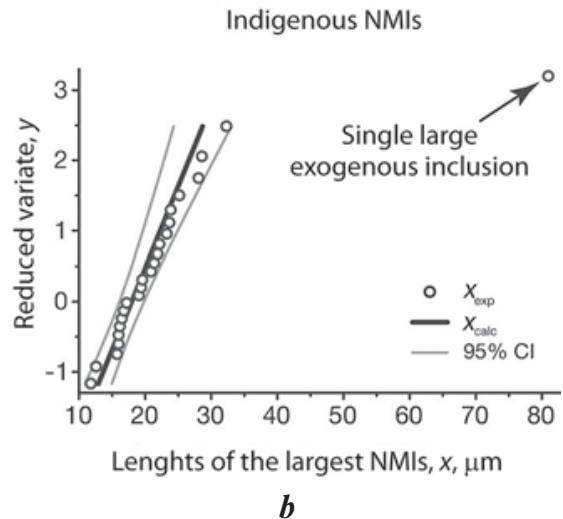

Exogenous NMIs from systemic source

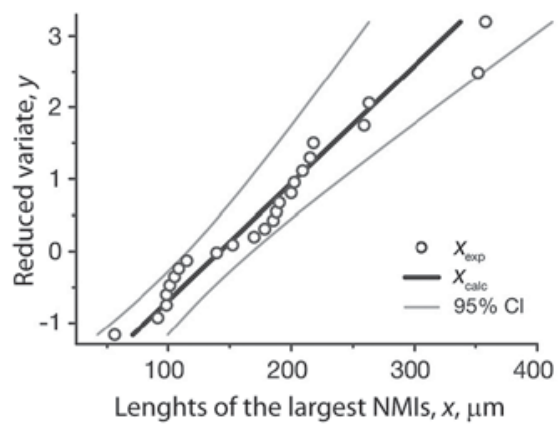

$d$

Fig. 2. Distribution for the reduced variate versus the lengths of the largest NMIs, Class $\mathrm{C}$ wheel steel of heats \#1 (a), \#2 (b), \#3 (c) and the top ring of the forging of the 420 ton ingot of the $15 \mathrm{Cr} 2 \mathrm{NiMoV}$ steel $(d)$
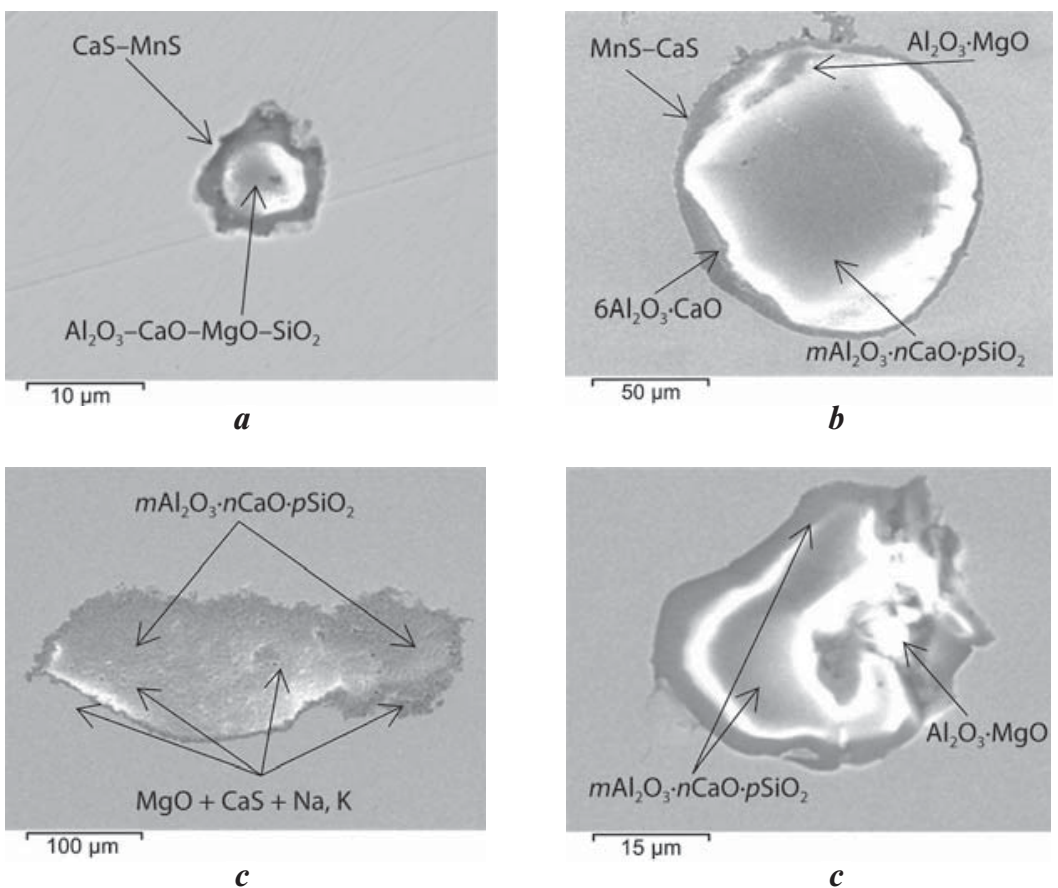

Fig. 3. Nonmetallic inclusions in the studied specimens:

$a$ - indigenous NMI in wheel steel, heat \#1; $b$ - single exogenous NMI in wheel steel, heat \#2; $c$ - exogenous sodium and potassium-containing $\mathrm{NMI}$ in wheel steel, heat \#3; $d$ - exogenous NMI in forging from an extralarge ingot of $15 \mathrm{Cr} 2 \mathrm{NiMoV}$ steel

plexity of the methods and do not comply with the current standard [18]. Therefore, we will use the assessment method described in ASTM E2283.

For each investigated heat of wheel steel, according to the method [13], which includes testing the hypothesis about the possibility of NMIs classification as small indigenous and large exogenous types [10], the unique theoretical distributions of Gumbel were found (Table 1).

Next, we evaluated how good the theoretical distributions were of the largest NMIs in each wheel from different heats, as well as from the forging of 420 tons' ingot of $15 \mathrm{Cr} 2 \mathrm{NiMoV}$ steel was selected (Fig. 2). The distributions of the reduced variate $(y)$ were calculated from the lengths of the largest NMIs according to equation 2 , and depending on the inclusion's nature how these distributions differed from each other.

It was previously shown [27, 28 ], and it was confirmed in the present paper, that small indigenous nonmetallic inclusions in wheel steel are the products of deoxidation and modification, and that they are liquid at the temperatures of ladle treatment and pouring off (Fig. 3, a). Such NMIs are well described by the theoretical distribution, and the experimentally found lengths of the largest NMIs are within the calculated confidence interval (see Fig. 2, a). This is an example of data processing in strict accordance with ASTM E2283.

In another heat of \#2 of wheel steel, along with small indigenous NMIs well described by the theoretical curve (see Fig. 2, b), one large NMI with a length of $80 \mu \mathrm{m}$ was found, which is far from the main distribution and beyond the confidence interval. Taking into account the inclusion's chemical composition, we can conclude that slag from a tundish accidentally fell into the melt and was entrapped in the continuously 
cast billet (see Fig. 2, b). Thus, ASTM E2283 can be used to recognize random, single large exogenous inclusion among the small indigenous deoxidation products.

We observed a completely different picture when analyzing the length of the NMIs in heat \#3 of the wheel steel (see Fig. 2, c). Here, the entire set of all measured largest NMI lengths was split into two separate sets by inclusions number and size: the first one with $95 \%$ of small inclusions and the second one with the remaining $5 \%$ of larger inclusions. The longest inclusions of this heat from the second set contain sodium and potassium (Fig. 3, c); therefore, they can be attributed to slag particles from mould flux entrapped in the mold. Such inclusions were constantly emulsified into a continuously cast billet due to the unsatisfactory work of the mould flux during the nonoptimal mode of blowing stoppers by argon [29]. For each of these sets, unique parameters of the Gumbel distribution were found (see Table 1). It can be concluded that we have separated the NMIs of different nature.

So, the ASTM E2283 practice was extended to evaluate exogenous inclusions and to estimate not only the small indigenous deoxidation products, but also the large exogenous inclusions entrapped by the melt on a regular (systemic) basis (see Fig. 2, c). It should be noted that the products from heat $\# 3$ were rejected not only during the initial acceptance tests, but also with additional extended control using an increased number of specimens.

Let us illustrate the new approach of ASTM E2283 usage on the distribution of inclusions found in the bottom ring of forging from the extra-large ingot of $15 \mathrm{Cr} 2 \mathrm{NiMoV}$ steel (see Fig. 2, d). An analysis of the composition and morphology of the longest NMIs found (see Fig. 3, d) shows that they have an exogenous nature; nevertheless, they are well described by the theoretical Gumbel distribution. As was shown [10, 30], the systemic source of such inclusions in the melt is the constant emulsification of the surface slag from a casting ladle during top pouring off.

Thus, Fig. 2 shows all possible ways to use the ASTM E2283 to describe the distribution of the reduced variate $(y)$ versus lengths of the largest NMIs of different nature:

- for indigenous deoxidation products in strict accordance with the standard (see Fig. 2, a);

- to identify a single exogenous NMI, the length of which is significantly larger than the mainstream indigenous inclusions-deoxidation products (see Fig. 2, b);

- for a separate description of not only the indigenous but the exogenous inclusions found in one specimen (see Fig. 2, c) or only for description of exogenous (see Fig. 2, d) inclusions found in another specimen, when all these exogenous inclusions in both specimens have a systemic source of penetration into the melt.

Let us notice that, except for the first case, the remaining cases relate to the extended use of ASTM E2283 developed in the present paper. If the length of the one single longest inclusion is outside of the confidence level of the Gumbel distribution for the indigenous inclusion

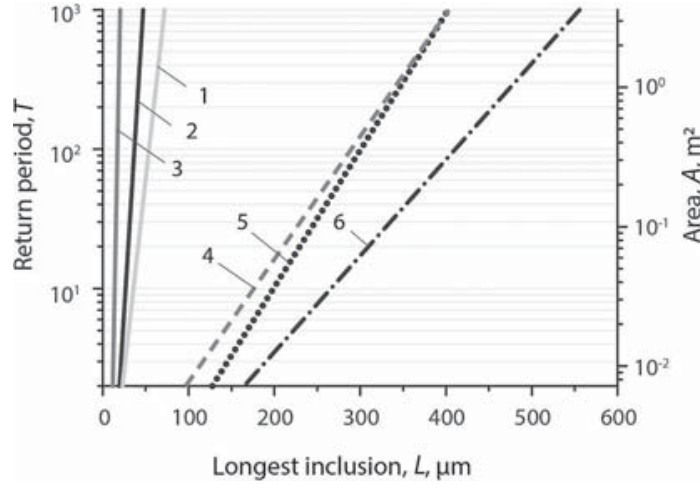

Fig. 4. Prediction of maximum inclusion length $\left(L_{\max }\right)$ for a return period $T$ and reference area $A_{\text {ref }}$ for all investigated specimens.

Indigenous NMIs: 1 - wheel steel \#1; 2 - wheel steel \#2; 3- wheel steel \#3;

Exogenous NMIs: 4 - wheel steel \#3; 5- bottom ring; $6-$ top ring; forging of $15 \mathrm{Cr} 2 \mathrm{NiMoV}$ steel

deoxidation products; then, its appearance in the melt is random, and to eliminate such exogenous NMIs, the culture of steel production practice should be improved.

Splitting all the longest NMIs on 5\% of number of the longest and $95 \%$ of number of the remaining smaller ones, we put forward a hypothesis that the first ones are the large exogenous inclusions, and the second ones are the fine indigenous deoxidation products.

This hypothesis is confirmed by SEM EDS method of the few representative inclusion compositions from indigenous and exogenous inclusions. Separated analysis of the Gumbel distribution for each type of NMI gives a final conclusion about their nature. If large exogenous NMIs are described by the unique Gumbel distribution with parameters typical only for them, this is an attribute of the presence of a systemic source of such NMIs entrapped by the melt, so by eliminating this source, the impurity rating of the nonmetallic inclusions can be significantly decreased and improved.

The approach described above allows not only to obtain important conclusions about the nature of the inclusions found, but also to expand the ASTM E2283 scope to exogenous nonmetallic inclusions.

\section{Assessment of the Largest NMIs in Steels}

To predict the longest inclusion $\left(L_{\max }\right)$ expected to be found in area $A_{\text {ref }}$ for all investigated specimens, extrapolation curves were calculated and plotted (Fig. 4):

$$
L_{\max }=-\delta \ln \left(-\ln \left(\frac{T-1}{T}\right)\right)+\lambda,
$$

where $T$ - return period is the number of areas that must be observed in order to find an inclusion equal to or larger than a specified maximum inclusion length.

The measurements were performed on the cross sections with an area of $A_{0}=150 \mathrm{~mm}^{2}$. The reference area $A_{\text {ref }}=150,000 \mathrm{~mm}^{2}$ for a return period of $T=1000$ [18]. 
Fig. 4 shows the predicted curves for NMIs in the studied specimens sampled from three wheels from three different heats of wheel steel, as well as from the bottom and the top rings of the forging made from an ingot of $15 \mathrm{Cr} 2 \mathrm{NiMoV}$ steel weighing 420 tons.

In railway wheels from heat \#1, over-modified by calcium, the predicted largest indigenous inclusion length was $72 \mu \mathrm{m}$ (see Fig. 4, line 1) and it exceeded the allowable NMI length for the acceptance test. In the wheel from heat \#2 with suboptimal deoxidation and modification practices, the predicted largest indigenous inclusion length was $47 \mu \mathrm{m}$ (see Fig. 4, line 2); while for the optimal deoxidation and calcium modification in heat \#3, this length was only $20 \mu \mathrm{m}$ (see Fig. 4, line 3).

Despite the fact that the wheel from heat \#3 has the lowest indigenous nonmetallic impurity rating, the predicted largest length of exogenous slag inclusion entrapped into the continuously casting billet from the systemic source due to the failures of pouring off and casting technology reaches $400 \mu \mathrm{m}$. For the same reason, the heat \#3 was twice rejected, first during the initial acceptance tests, then with extended control on an increased number of specimens.

In forging from an extra-large ingot with the same results as in the wheel steel with a low level of indigenous NMIs [10], the predicted largest length of exogenous NMIs reaches $400 \mu \mathrm{m}$ and $555 \mu \mathrm{m}$ in the bottom ring and top ring of the forging, respectively.

Thus, it is shown that, regardless of the methods of steelmaking technology all of them provide a sufficiently low level of indigenous nonmetallic impurity ratings in super duty steels. However, failures of pouring off and casting technology lead to contamination of the finished metal with inclusions up to $400-555 \mu \mathrm{m}$ in length not only in the case of casting extra-large ingots from $15 \mathrm{Cr} 2 \mathrm{NiMoV}$ steel, but also during continuous casting of high-quality wheel steel billets.

\section{Conclusions}

1. The examples of using the extreme value analysis, implemented in ASTM E2283, to predict longest inclusion expected to be found in super duty steels have been discussed.

2. An original method of interpretation of measurement results obtained according to ASTM E2283 has been proposed, which allows expanding the scope, as well as significance and use of this standard to exogenous inclusions.

3. It has been shown that the ASTM E2283 practice can be used to identify random single large exogenous inclusions among all detected indigenous inclusion deoxidation products, as well as to predict the largest length of exogenous inclusions if they have a systemic source of penetration into the melt and are described by the corresponding Gumbel distribution.

4. It has been shown that the current level of ladle treatment provides the low level of indigenous NMIs in super duty steels; however, failures in pouring off and casting technology can lead to significant contamination of the finished metal with exogenous inclusions.

\section{REFERENCES}

1. Murakami Y. Metal Fatigue: Effects of Small Defects and Nonmetallic Inclusions. Tokyo, Yokendo Ltd. 1993. pp. $75-122$.

2. Gubenko S. I., Parusov V. V., Derevyanchenko I. V. Nonmetallic Inclusions in Steel. Donetsk: Art-Press. 2005. 225 p.

3. Durynin V. A., Solntsev Yu. P. Study and Improvement of the Production Technology to Increase Resource of Steel Articles from Large-Sized Forged Pieces for Critical Applications. Saint-Petersburg: Khimizdat. 2006. 272 p.

4. Smirnov A. N., Makulov S. L., Safonov V. M., Tsuprun A. Yu. Large Sized Ingot. Donetsk: DonNTU. 2009. 278 pgs.

5. Durynin V. A., Titova T. I., Matveev G. P., Balandin S. Yu. Study of Quality of the Large-Sized Shell Made from 15Cr2NiMoVA Steel 360t Ingot for a Nuclear Reactor, Elektrometallurgiya. 2003. No. 9. pp. 45-48.

6. Dub V. S., Romashkin A. N., Malygin A. N. Basic Trends in Development of the Technology for Steel Casting in Ingots. Metallurg. 2013. No. 6. pp. 31-34.

7. Gurovich B. A., Kuleshova E. A., Fedotova S. V., Frolov A. S., Maltsev D. A. Phase Transformations in Materials of Check Test Pieces during Long-Run Temperature Holding at Working Temperatures of VVER-1000 Reactor Shells. Tyazheloe mashinostroenie. 2012. No. 7. pp. 22-26.

8. Gurovich B. A., Kuleshova E. A., Maltsev D. A., Fedotova S. V., Frolov A. S. Relationship Working Characteristics of Nuclear Reactor Shell Steels with Evolution of their Nanostructure under Action of Working Temperature and Radiation. Fizika Radiatsionnykh Povrezhdeni i Radiatsionnoe Materialovedenie. 2013. No. 2(84). pp. 3-10.

9. Gurovich B. A., Kuleshova E. A., Artamonov M. A., Erdak A. D. Comparative Features of Brittle Fracture Initiation in COD-type Samples of VVER-1000 Reactor Basic Metal and Weld Joint Metal after Testing on Crack Growth Resistance. Proceedings of the VIII International Scientific and Technical Conference "Accident prevention of VVER NPP". 28-31 May 2013. Podolsk. pp. 1-8.

10. Kazakov A. A., Zhitenev A. I., Kolpishon E. Yu., Salynova M. A. Nonmetallic Inclusions Quantitative Assessment for Forgings Made from Super Large Steel Ingot. Chernye Matally. 2018. No. 12. pp. 50-56.

11. AAR Specification $M-107 / M-208$. Standard for Wheels, Wrought Carbon Steel. 2017. 8 p.

12. ASTM E1245-03. Standard Practice for Determining the Inclusion or Second-Phase Constituent Content of Metals by Automatic Image Analysis. 2003, 8 p.

13. Kazakov A. A., Zhitenev A. I., Salynova M. A. Estimation of Single Large Nonmetallic Inclusions in Steel Using Statistics of Extreme Values. Chernye Metally. 2018. No. 11. pp. 70-74.

14. Spektor Ya. I., Lyashenko V. P., Samsonov A. N. Study of Fatigue Microcracks and Nonmetallic Inclusions. Stali i Nemetallicheskie Vklyucheniya. 1980. No. 4. pp. 30-38.

15. Gumbel E. J. Statistics of Extremes. Columbia University Press. New York. 1958. pp. 349-358. 
16. Murakami Y. Inclusion Rating by Statistics of Extreme Values and Its Application to Fatigue Strength Prediction and Quality Control of Materials. Journal of Research of the National Institute of Standards and Technology. 1994. Vol. 99. No. 4. pp. 345-351.

17. Lipiński T., Wach A., Detyna E. Influence of Large Nonmetallic Inclusions on Bending Fatigue Strength of Hardened and Tempered Steels. Advances in Material Science. 2015. Vol. 15. No. 3 (45). September. pp. 33-40.

18. ASTM E2283-08. Standard Practice for Extreme Value Analysis of Nonmetallic Inclusions in Steel and Other Microstructural Features. 2008, 11 p.

19. Kanbe Y., Karasev A., Todoroki H., Jonsson Par G. Application of Extreme Value Analysis for Two- and Three-Dimensional Determinations of the Largest Inclusion in Metal Samples. ISIJ International. 2011. Vol. 51. Iss. 4. pp. 593-602.

20. Kanbe Y., Karasev A., Todoroki H., Jonsson Par G. Analysis of Largest Sulfide Inclusions in Low Carbon Steel by Using Statistics of Extreme Values. Steel Research Int. 2011. Iss. 82. pp. 313-322.

21. Beretta S., Murakami Y. Largest-Extreme-Value Distribution Analysis of Multiple Inclusion Types in Determining Steel Cleanliness. Metall. Mater. Trans. B. 2001. Vol. 32B. pp. 517-523.

22. Schmiedt A. B., Dickert H. H., Bleck W., Kamps U. Multivariance Extreme Value Analysis and its Relevance in a Metallographical Application. Journal of Applied Statistics. 2014. Vol. 41. No. 3. pp. 582-595. DOI: 10.1080/02664763.2013.845872

23. Beretta S., Anderson C. W. Extreme Value Statistics in Metal
Fatigue. Societa Italiana di Statistica: Atti Della XLI Riunione Scientifica. 2002. pp. 251-260.

24. Ekengren J., Bergstrom J. Extreme Value Distributions of Inclusions in six Steels. Extremes. 2012. No. 15. pp. 257-265.

25. Zhang J. M., Zhang J. F., Yang Z. G., Li G. Y., Yao G., Li S. X., Hui W. J., Weng Y. Q. Estimation of Maximum Inclusions Size and Fatigue Strength in High-Strength ADF1 Steel, Materials Science and Engineering. 2005. No. 394. pp. 126-131.

26. Trushnikova A. S. The Use of Mathematical Statistics Methods for Predicting the Content of Large Nonmetallic Inclusions in Steel. Proceedings of V Russian Conference of Young Researches. Promising materials. Special Issue. 2008. pp. 244-246.

27. Kazakov A. A., Zhitenev A. I., Ryaboshuk S. V. Interpretation and Classification of Nonmetallic Inclusions. Materials Performance and Characterization. 2016. pp. 535-543.

28. Kazakov A. A., Zhitenev A. I. Assessment and Interpretation of Nonmetallic Inclusions in Steel. CIS Iron and Steel Review. 2018. Vol. 16. pp. 33-38.

29. Thomas B. G. Mathematical Modeling of the Continuous Slab Casting Mold: A State-of-the-Art Review. 74th Steelmaking Conference Proceedings. Warrendale. PA. Iron and Steel Society, 1991. pp.105-118.

30. Titova T. I., Bocharov S. A., Ratushev D. V., Malykhina O. Yu. Afanaseva L. T., Efimov S. V. Study of Nonmetallic Inclusions in Metal of Reactor Shell Workpiece from the Steel 15Cr2NiMoVA in Dependence on the Technology for Manufacturing Large-Sized Ingots. Proceedings of the X International Scientific and Technical Conference "Accident Prevention of VVER NPP". 16-19 May 2017. pp. 1-5.

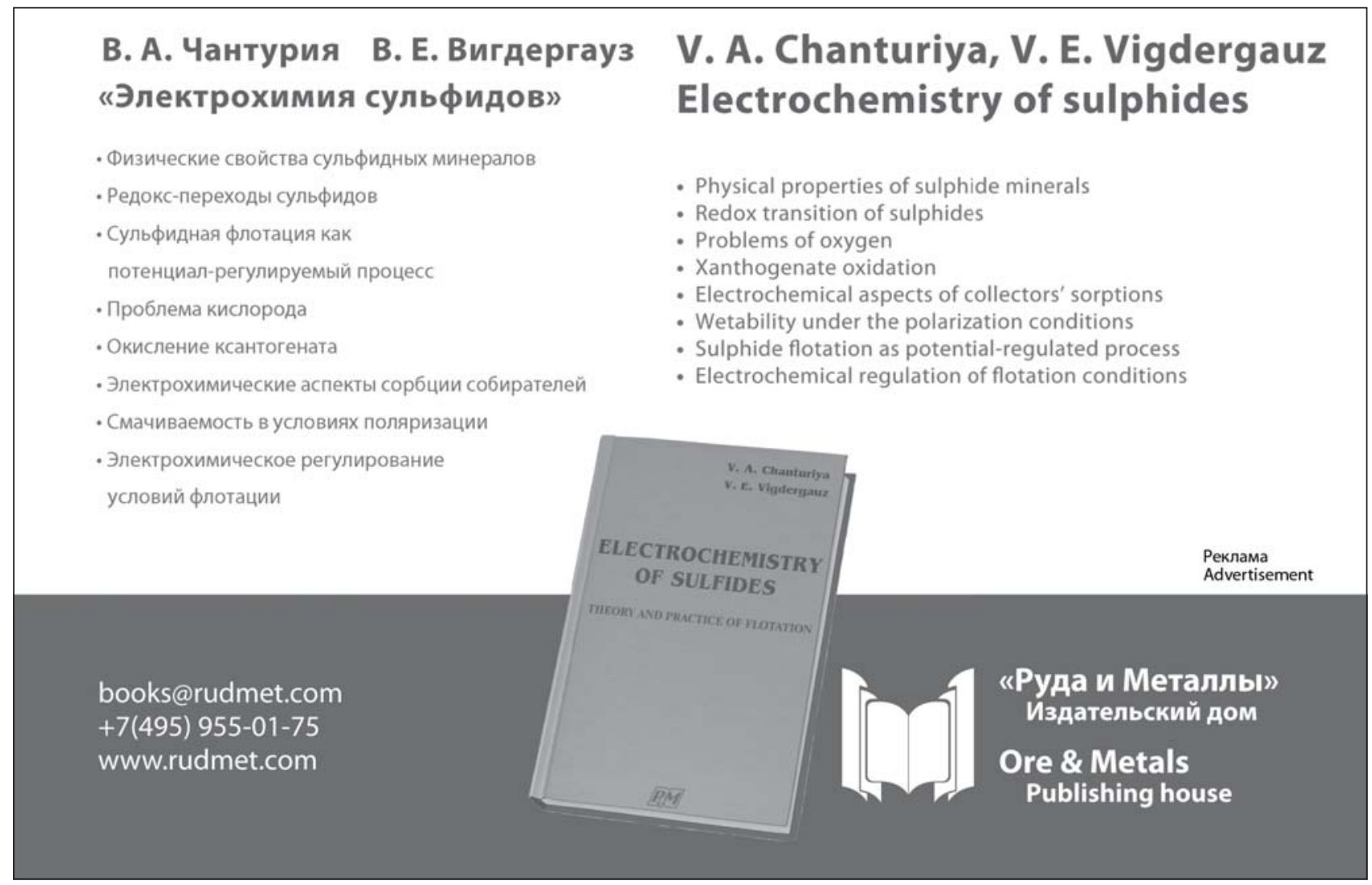

